\title{
REVIEW
}

\section{PROSPEK KAYU KUALITAS RENDAH DAN KURANG DIKENAL SEBAGAI SUBSTITUSI KAYU KOMERSIAL}

\author{
The Prosfect Improvement of Wood Low Strenght \\ at Graded of Woods Commercial Substitution
}

Effendi Arsad

Balai Riset dan Standardisasi Industri Banjarbaru

JI. P. Batur Barat No.2. Telp.(0511) 4772461-4774861 Banjarbaru

E-mail : baristand.banjarbaru@gmail.com

Diterima 05 Mei 2013, disetujui 31 Mei 2013

\begin{abstract}
ABSTRAK
Pada saat ini kayu dengan kualitas tinggi sulit didapat dan harganya relatif mahal. Oleh karena itu, konstruksi bangunan perumahan mulai menggunakan jenis-jenis kayu kualitas rendah. Penggunaan bahan baku tersebut menjadikan mutu bangunan kurang baik. Hal itu menyebabkan bangunan tidak tahan lama, mudah terserang organisme perusak seperti rayap dan organisme lainnya. Agar bangunan menjadi berkualitas maka diperlukan upaya perbaikan mutu bahan baku kayu kualitas rendah tersebut. Perbaikan kayu kualitas rendah bisa dilakukan dengan banyak cara, antara lain pengawetan dengan cara tradisional seperti perendaman dalam air, pemendaman dalam lumpur, pengeringan, pengasapan dan perendaman dalam air panas. Selain itu pengawetan dengan menggunakan bahan kimia cukup banyak, seperti menggunakan Natrium Hidroksida $(\mathrm{NaOH}), \mathrm{CCB}, \mathrm{CCF}$ dan lainnya, bisa dilakukan dengan cara perendaman dan perebusan dalam larutan tersebut. Jenis kayu kelas kuat rendah seperti kayu kembang kelas III, kayu tarap kelas V, kayu durin kelas III, kayu lua kelas IV dan kayu kelampayan kelas IV, semuanya termasuk kayu kelas kuat III - V.
\end{abstract}

Kata kunci : kayu non komersial, fisik, mekanik, pengawetan

\begin{abstract}
At this time the wood with a high quality hard to find and expensive. There for, construction of residential buildings began to use other types of low-quality wood strong. The use of raw materials to make buildings less good quality. It causes no long lasting building, susceptible organisms such as termites and other destructive. In order to bequalified building efforts are needed to improve the quality of the raw material of low quality wood strong, with a variety of technical. Strong improvement in the quality of low quality wood can be done in many ways, including preservation using chemicals such as by way of soaking and boiling in a solution of Sodium Hydroxide (NaOH), CCB, CCF and itc. Performed with the compression heat. Strong low quality wood species used is lua timber, lumber and wood tarap flowers, pressure felts give better results than treatment at others. Three types of wood used is solid wood class III - V increased the flower timber strength class III, wood tarap class V, wood durin class III, solid wood lua IV and wood kelampayan IV while the wood all is showed no improvement.
\end{abstract}

Keywords: wood non commercial, physical, mechanical, preservation

\section{PENDAHULUAN}

$\mathrm{Di}$ Indonesia tumbuh sedikitnya di Indonesia. Beberapa diantaranya 4.000 jenis kayu yang tersebar di hutan termasuk jenis kayu komersial, kayu 
kurang dikenal dan sangat kurang dikenal (Sunardiyanto E, 2012). Dari 4000 jenis kayu tersebut diatas diperkirakan 400 jenis dianggap penting karena merupakan jenis yang sekarang sudah dimanfaatkan dan diketahui sifat dan kegunaannya, sedangkan 259 jenis diantaranya sudah dikenal dalam perdagangan, sedangkan sisanya masih belum dikenal (Lesser known species). Potensi kayu tersebut terdapat dalam jumlah yang besar dan berperan penting pada masa yang akan datang sebagai substitusi kayu komersial, Permasalahan yang dihadapi saat ini oleh industri perkayuan di Indonesia adalah kurangnya pasokan bahan baku kayu. Berdasarkan pendataan bersama antar Departemen Kehutanan dan Departemen Perindustrian dan Perdagangan jumlah Industri Primer Hasil Hutan Kayu (IPHHK) sebanyak 1.540 unit, dengan kebutuhan kayu diperkirakan 63,48 juta $\mathrm{m}^{3}$ per tahun (Laban, 2005). Pasokan kayu dari hutan alam yang legal hanya berkisar 3 juta $\mathrm{m}^{3}$. Penurunan produksi ada kecendrungan karena keberadaan potensi hutan alam semakin berkurang, sehingga berpengaruh terhadap industri penggergajian kayu untuk memenuhi kebutuhan masyarakat. (Harsono D, 2008).

Kayu merupakan sumber kekayaan alam yang mudah diproses sesuai keperluan penggunaannya. Baik berbentuk kayu pertukangan, kayu industri maupun kayu bakar (Ismediyanto, 2008). Disamping itu kayu juga memiliki komponen kimia seperti makromolekul utama dinding sel yaitu selulosa, poliosa dan lignin yang terdapat pada semua kayu dan komponenkomponen yang ringan (ekstraktif dan zatzat mineral).

Perbandingan komposisi kimia lignin dan poliosa berbeda pada kayu lunak dan kayu keras, sedangkan selulosa merupakan komponen yang seragam pada semua jenis kayu (Mardikanto, 2011).

Kayu komersial yang berkualitas banyak digunakan untuk pembangunan gedung, pertokoan, rumah ibadah, dan perumahan, seperti kayu meranti, lanan dan lainnya. Sekarang dengan semakin meningkatnya harga kayu yang berkualitas dan potensinya mulai menurun serta permintaan semakin meningkat, seiring dengan kemajuan dibidang pembangunan perumahan penduduk dan mebel. Hal itu menyebabkan banyaknya orang menggunakan jenis kayu yang tidak sesuai dengan penggunaannya seperti kayu kualitas rendah, sehingga bahan baku bangunan kurang baik. Oleh karena itu perlu upaya peningkatan mutu kayu kualitas rendah. Kayu kualitas rendah masuk kategori kelas kuat $\mathrm{V}$ - IV dengan berat jenis $0,3-0,6$, kuat lentur $300-500$ $\mathrm{kg} / \mathrm{cm} 2$, kuat tekan $215-300 \mathrm{~kg} / \mathrm{cm} 2$. Kegunaan kayu tersebut terbatas untuk bahan- bahan produk yang tidak menahan beban, seperti ukir-ukiran, kerajinan dan lainnya (Soewarsono PH. (1990) di dalam Jurnal Riset Industri Hasil Hutan, (2010). Menurut Suroto, (2007). Jenis-jenis kayu yang masuk kualitas rendah umumnya masuk kelas kuat III sampai kelas kuat V. Pemanfaatan kayu tersebut agar maksimal seperti kayu kelas kuat I dan II, maka perlu upaya perbaikan sifat dari jenis kayu tersebut dengan teknik pemadatan atau pengempaan. Meskipun ada beberapa diantaranya sudah digunakan secara lokal, tetapi karena kondisinya kurang menarik, menyebabkan kurang laku untuk dikomersilkan dipasaran. Upaya meningkatkan jenis kayu kualitas rendah tersebut menjadi bermutu, maka diperlukan beberapa jenis bahan finishing kayu, sehingga diharapkan produk kayu yang dihasilkan memiliki bentuk warna yang cukup menarik sesuai dengan selera konsumen. Bahan finishing yang digunakan untuk kayu ada 2 macam, yaitu zat pengkilap (clear glass) yang merubah warna bentuk kayu dan zat pengkilap yang tidak merubah warna kayu. Menurut Martono D. 2010. Pemberian wood stain (pewarna) pada permukaan kayu dalam proses finishing adalah memberi efek warna yang diinginkan dengan tanpa menyembunyikan atau mengaburkan gambar serat kayu.

Penelitian kayu kualitas rendah sudah banyak dilakukan oleh para peneliti. Jenis kayu tersebut seperti kayu kembang (Goniothalamus SP), kayu tarap (Arthocarpus SP), kayu durian (Durio zibethinus), kayu lua (Ficus Glomevata 
Roxb), kayu kelampayan (Anthocephalus spp), dan lainnya.

Penelitian dimaksudkan untuk mengetahui sifat fisis mekanis kayu tersebut seperti (kuat lentur, kuat tekan dan kekerasan), sesuai dengan penggunaannya, ditinjau dari sifat fisis mekanis kayu. Terdapat beberapa kelemahan bila jenis kayu kualitas rendah digunakan untuk bahan baku mebel, diantaranya kelas kuat dan kelas awet yang rendah, sehingga hal itu menyebabkan kurang menarik bagi konsumen.

\section{POTENSI KAYU KELAS KUAT RENDAH}

Kayu merupakan salah satu bahan penting untuk pembangunan dan kebutuhan industri pengolahan kayu yang hingga saat ini berkembang pesat termasuk industri kerajinan dan mebel. Walaupun saat ini ada bahan konstruksi seperti baja, besi, alumenium dan produk lainnya, tetapi kayu masih digunakan untuk bermacam - macam kebutuhan pembangunan dan industri. Penggunaan kayu harus diketahui sifat-sifat kayu agar dapat dimanfaatkan secara optimal dari segi teknis maupun ekonomis. (Saibatul Hamdi, 2010).

Menurut Martawijaya dan Kartasudjana (1981) di dalam Krisdianto, (2006) Indonesia memiliki banyak jenis pohon berkayu, diperkirakan terdapat sekitar 4000 jenis kayu, namun hanya sekitar 400 jenis kayu (10\%) yang sudah diketahui jenis dan kegunaannya. Dari 400 jenis tersebut baru sebagian saja yang sudah diketahui sifat fisis dan mekanis, kegunaannya dan sudah dikenal dalam perdagangan. Sisanya merupakan kayu kurang dikenal dan termasuk jenis-jenis kayu kualitas rendah. Kayu kualitas rendah ada kecendrungan terdapat di semua Propinsi yang ada di wilayah Indonesia dari Sabang sampai Merauke.

\section{SIFAT FISIK KAYU}

Sifat fisik kayu merupakan sifat yang berhubungan dengan kayunya secara fisik.
Sifat fisik yang dimaksudkan meliputi kerapatan, berat jenis, kadar air, kembang susut, sifat kayu terhadap panas, listrik, ketahanan kayu terhadap zat, terhadap cuaca, ketahanan kayu terhadap pelapukan dan sebagainya, (Nurwati H.MS, 2004). Sedangkan ada pula yang membagi sifat fisik kayu terdiri dari : Kadar air, Berat jenis, keawetan alami, warna, Higroskopis, Tekstur dan Serat kayu. Pengujian sifat fisik kayu menggunakan ASTM D - 143 - 52.

\subsection{Kadar air}

Pengertian Kadar air kayu biasanya dinyatakan dalam persen, merupakan perbandingan antara berat air dengan berat kayunya sendiri yang bebas air. Kadar air 50\% mengandung pengertian bahwa berat air dalam kayu atau dalam rongga sel dan dinding sel sama dengan $50 \%$ dari berat kayu kering tanur. Maka kadar air 200\% berarti berat air dalam kayu = dua kali berat kayunya dalam keadaan kering tanur. (Nurwati, 2004). Kadar air kayu umumnya dipengaruhi oleh kadar air awal kayu, jenis kayu, zat ekstraktif dan proses pengeringan atau pengawetan.

Berdasarkan Kadar air kayu untuk pemakaian kayu pada suhu dan kelembaban udara, sebagai berikut :

- Kayu aman dari serangan jamur pewarna kadar air 20\%.

- Pintu luar, alat pertanian kadar air 17 $16 \%$.

- Kayu untuk produk interior kadar air $15 \%$.

- Produk interior yang kadang-kadang dipanasi atau ber AC kadar air $14-13 \%$

- Mebel, lantai blok kayu dan barangbarang kayu dalam ruangan yang terus menerus dipanasi atau ber - AC kadar air $12-11 \%$.

- Barang- barang kayu yang letaknya dekat dengan sumber panas atau ber AC kadar air $10 \%$.

- Lantai kayu yang diatasnya ada pemanas kadar air $9-8 \%$.

\section{2. Berat Jenis}

Kayu memiliki berat jenis yang berbeda-beda. Berat jenis merupakan petunjuk penting bagi aneka sifat kayu. 
Makin berat kayu, umumnya makin kuat pula kayunya. Semakin ringan suatu jenis kayu akan berkurang pula kekuatannya. Berat jenis kayu diperoleh dari perbandingan antara berat volume kayu tertentu dengan volume air yang sama pada standar.

Menurut J.F. Dumanauw, (2007), membagi berat jenis kayu menjadi 4 kelas.

Tabel 1. Kelas Kayu Berdasarkan Berat Jenisnya

\begin{tabular}{lc}
\multicolumn{1}{c}{$\begin{array}{c}\text { Kelas Bobot } \\
\text { Kayu }\end{array}$} & Berat Jenis Kayu \\
\hline a. Sangat berat & Lebih besar dari 0,90 \\
\hline b. Berat & $0,75-0,90$ \\
\hline c. Agak berat & $0,60-0,75$ \\
\hline d. Ringan & Lebih kecil dari 0,60 \\
\hline
\end{tabular}

\subsection{Keawetan Kayu Alami}

Keawetan kayu alami dimaksud ialah ketahanan kayu terhadap serangan dari organisme perusak kayu seperti : jamur rayap, bubuk, cacing laut dan mahluk lainnya yang diukur dengan jangka waktu tahunan. Keawetan kayu tersebut disebabkan oleh adanya zat di dalam kayu yang merupakan unsur racun bagi perusak kayu, sehingga perusak tersebut tidak sampai masuk dan tinggal di dalamnya serta merusak kayu. Misalnya kayu jati memiliki tectoquinon, kayu ulin memiliki silika dan lainnya.

\subsection{Warna Kayu}

Beberapa macam warna kayu diantaranya warna kuning, keputih-putihan, coklat muda, coklat tua, kehitam-hitaman, kemerah-merahan dan sebagainya. Hal itu disebabkan zat-zat pengisi warna dalam kayu yang berbeda-beda. Warna suatu jenis kayu dapat dipengaruhi oleh faktor tempat di dalam batang, umur pohon dan kelembaban udara.

\subsection{Higroskopis}

Kayu mempunyai sifat higroskopis yaitu dapat menyerap dan melepaskan air atau kelembaban. Selanjutnya masuk dan keluarnya air dari kayu menyebabkan kayu itu basah atau kering, akibatnya kayu itu akan mengembang atau menyusut.

\subsection{Tekstur kayu}

Tekstur adalah ukuran relatif sel-sel kayu. Sel kayu ialah serat-serat kayu, jadi dapat dikatakan tekstur ialah ukuran relatif serat-serat kayu. Berdasarkan teksturnya, kayu dapat digolongkan ke dalam :

- Kayu bertekstur halus, seperti giam, lara, kulim dan lainnya.

- Kayu bertekstur sedang, seperti jati, sonokeling dan lainnya.

- Kayu bertekstur kasar, seperti meranti, kempar dan lainnya.

\subsection{Serat kayu}

Kayu dikatakan berserat lurus, jika arah sel-sel kayunya sejajar dengan sumbu batang. Kalau sel-sel itu menyimpang atau membentuk sudut terhadap sumbu panjang batang, dikatakan kayu itu berserat mencong. Serat mencong dapat dibagi menjadi :

- Serat terpadu

- Serat ber-ombak

- Serat terpilin dan

- Serat diagonal

\subsection{Kerapatan Kayu}

Kerapatan kayu adalah massa atau berat kayu per unit volume kayu. Kerapatan merupakan faktor penting untuk mengetahui sifat fisis dan mekanis kayu (Nurwati H, (2004). Kerapatan kayu dipengaruhi oleh struktur anatomi kayu (serat kayu, trakeida, saluran resin, rongga sel dan tebal dinding sel), serta dipengaruhi oleh kehadiran zat-zat lain, misalnya zat ekstraktif (Kollman dan Cote, 1968 di dalam Nurwati, H, (2004).

Kerapatan kayu biasa dinyatakan dalam satuan berat per satuan volume $(\mathrm{kg} / \mathrm{cm} 3)$.

\section{SIFAT MEKANIK KAYU}

Sifat mekanik kayu ialah kemampuan kayu untuk menahan beban dari luar. Maksudnya ialah gaya-gaya dari luar benda yang mempunyai kecenderungan untuk mengubah bentuk dan besarnya benda. Kekuatan kayu memegang peranan penting dalam penggunaannya sebagai bahan bangunan. Hal yang erat hubungannya dengan kekuatan kayu adalah sifat mekanik kayu. Kekuatan kayu menentukan banyaknya bahan yang 
Prospek Kayu Kualitas Rendah dan Kurang Dikenal

Sebagai Substitusi Kayu Komersial ......Effendi Arsad

dimanfaatkan. Perubahan bentuk yang terjadi segera sesudah beban dapat dipulihkan. Jika beban dihilangkan disebut perubahan elastis.

Sifat-sifat mekanis kayu yang berhubungan dengan kekuatan kayu :

Wahyu, (2008) mengemukakan faktorfaktor alam yang bisa mempengaruhi sifat fisik mekanik kayu dapat dikelompokkan menjadi jenis kayu, tempat tumbuh, umur, letak dalam batang, diameter dan lain-lain.

\subsection{Keteguhan Tarik}

Kekuatan atau keteguhan tarik suatu jenis kayu ialah kekuatan kayu untuk menahan Gaya - gaya yang berusaha menarik kayu itu. Kekuatan tarik terbesar pada kayu sejajar dengan arah serat. Kekuatan tarik tegak lurus arah serat lebih kecil daripada kekuatan tarik sejajar arah serat. Keteguhan tarik ini mempunyai hubungan dengan ketahanan kayu terhadap pembelahan. Hal itu disebabkan perbedaan struktur ketiga jenis kayu tersebut. Sulistiyono dkk. (2002). mengemukakan struktur kayu yang berongga mengalami pengurangan tebal yang lebih besar dibanding kayu yang berstruktur lebih padat.

\subsection{Kuat Tekan (MOR)}

Kuat tekan suatu jenis kayu adalah kekuatan kayu untuk menahan muatan jika kayu itu dipergunakan untuk tujuan tertentu. Dalam hal ini dibedakan dua macam kompresi, yaitu kompresi tegak lurus arah serat dan kompresi sejajar arah serat. Keteguhan kompresi tegak lurus serat menentukan ketahanman kayu terhadap beban, seperti halnya berat rel kereta api terhadap bantalan dibawahnya. Keteguhan tersebut mempunyai hubungan juga dengan kekerasan kayu dan keteguhan geser. Keteguhan kompresi tegak lurus arah serat pada semua kayu lebih kecil dibandingkan keteguhan kompresi sejajar arah serat.

\subsection{Keteguhan Lentur (MOE)}

Keteguhan lentur ialah kekuatan kayu untuk menahan gaya-gaya yang berusaha melengkungkan kayu atau untuk menahan beban-beban mati maupun hidup selain beban pukulan yang harus dipikul oleh kayu tersebut, misalnya blandar. Dalam hal ini dibedakan keteguhan lengkung statik dan lengkung pukul. Keteguhan lengkung statis menunjukkan kekuatan kayu menahan gaya yang mengenainya secara perlahan-lahan. Adapun keteguhan lengkung pukul adalah kekuatan kayu, menahan gaya yang mengenainya secara mendadak, misalnya pukulan.

\subsection{Kekerasan}

Kekerasan kayu ialah suatu ukuran kekuatan kayu dalam menahan gaya yang membuat takik atau lekukan padanya. Kekerasan kayu juga dapat diartikan sebagai kemampuan kayu untuk menahan kikisan (abrasi). Dalam pengertian yang lain kekerasan kayu bersamaan dengan keuletannya merupakan bahan ukuran tentang ketahanannya terhadap pengausan kayu. Hal ini merupakan suatu pertimbangan untuk menentukan apakah suatu jenis kayu yang akan digunakan sebagai lantai rumah, balok pengerasan, pelincir sumbu, dan lain-lain. Kekerasan dalam arah sejajar serat pada umumnya melampaui kekerasan kayu dalam arah yang lain.

\subsection{Keteguhan Belah}

Sifat ini digunakan untuk menyatakan kekuatan kayu dalam menahan gaya gaya yang berusaha membelah kayu. Tegangan belah adalah suatu tegangan yang terjadi karena adanya gaya yang berperan sebagai baji. Sifat keteguhan belah yang rendah sangat baik untuk pembuatan sirap ataupun pembuatan kayu bakar. Sebaiknya keteguhan belah yang tinggi sangat baik untuk pembuatan ukirukiran (patung). Sebagai contoh kayu ulin baik untuk pembuatan sirap kayu sawo baik untuk pembuatan patung ataupun popor senjata dan lain sebagainya.

Tabel 2. Kekuatan Kayu Menurut Berat Jenisnya

\begin{tabular}{cccc}
\hline $\begin{array}{c}\text { Kelas } \\
\text { Kuat }\end{array}$ & $\begin{array}{c}\text { Berat Jenis } \\
\text { Kering } \\
\text { Udara }\end{array}$ & $\begin{array}{c}\text { Keteguhan } \\
\text { Lentur } \\
\text { Mutlak }\left(\mathrm{kg} / \mathrm{cm}^{2}\right)\end{array}$ & $\begin{array}{c}\text { Keteguhan } \\
\text { Tekan } \\
\text { Mutlak } \\
\left(\mathrm{kg} / \mathrm{cm}^{2}\right)\end{array}$ \\
\hline I & $>30,90$ & 1100 & $>650$ \\
\hline II & $0,90-0,60$ & $1100-725$ & $650-425$ \\
\hline III & $0,60-0,40$ & $725-500$ & $425-300$ \\
\hline IV & $0,40-0,30$ & $500-360$ & $300-215$ \\
\hline V & 0,30 & 360 & 215 \\
\hline
\end{tabular}

Sumber: J.F. Dumanauw 2007 


\section{SIFAT KIMIA KAYU}

Komponen kimia di dalam kayu mempunyai arti yang penting karena menentukan kegunaan suatu jenis kayu. Dengan mengetahuinya, kita juga dapat membedakan jenis-jenis kayu. Susunan kimia kayu digunakan sebagai pengenal ketahanan kayu terhadap serangan mahluk perusak kayu, selain itu dapat pula menentukan pengerjaan dan pengolahan kayu, sehingga didapat hasil yang maksimal. Pada umumnya komponen kimia kayu daun lebar dan kayu daun jarum terdiri dari tiga macam unsur yaitu (1) Karbohidrat yang terdiri dari selulosa dan hemeselulosa, (2) unsur non karbohidrat yang terdiri dari lignin,(3) unsur yang diendapkan dalam kayu selama proses pertumbuhan yang sering disebut zat ekstraktif.

Tabel 3. Klasifikasi Komponen Kimia Kayu

\begin{tabular}{llcl}
\hline Komponen & \multicolumn{3}{c}{ Kelas Komponen (\%) } \\
\cline { 2 - 4 } \multicolumn{1}{c}{ Kimia } & Tinggi & Sedang & Rendah \\
\hline Selulosa & $>45$ & $40-45$ & $>40$ \\
\hline Holoselulosa & $>33$ & $18-33$ & $>18$ \\
\hline Lignin & $>24$ & $21-24$ & $>21$ \\
\hline Zat Eksraktif & $>4$ & $2-4$ & $>2$ \\
\hline Kadar Abu & $>6$ & $0,2-6$ & $>0,2$ \\
\hline
\end{tabular}

Sumber : Pasaribu dkk, (2007)

\section{PENGAWETAN KAYU}

Keawetan kayu berhubungan erat dengan pemakaiannya. Kayu dikatakan awet jika mempunyai umur pakai lama. Kayu berumur pakai lama jika mampu menahan bermacam-macam faktor perusak kayu. Guna kepentingan tersebut bisa dilakukan dengan cara tradisional seperti perendaman dalam air berlumpur, pengeringan dipanas matahari, perebusan dan pengasapan. Cara ini tidak memerlukan biaya yang cukup tinggi Perendaman dalam air atau dalam lumpur dimaksudkan adalah melarutkan atau menghilangkan kandungan pati yang ada dalam kayu. Sedangkan pengawetan dengan cara pengeringan dipanas matahari maksudnya adalah mengurangi kandungan air yang terdapat dalam kayu mencapai kurang lebih 14\%. Pengawetan dengan cara perebusan hampir sama dengan perendaman dalam air, namun cara ini lebih efektif dan dapat mempengaruhi zat ektraktif yang lainnya. Sedangkan pengawetan dengan cara pengasapan dimaksudkan adalah mengurangi kadar air pada kayu dan zat ekstraktif dalam kayu serta dapat memberikan warna tertentu pada kayu yaitu warna menjadi agar ke kuningkuningan.

Pengawetan dengan cara kimiawi : Pengawetan dengan cara ini adalah pengawetan yang umum dilakukan orang pada saat ini termasuk dalam bidang penelitian. Namun pengawetan seperti ini harus mengacu pada ketentuan dan aturan tertentu. Pengawetan dengan bahan kimia harus mengacu pada Standar Nasional Indonesia (SNI), sehingga dapat mengurangi pengaruh terhadap kesehatan dan lingkungan sekitarnya. Dengan menggunakan bahan kimia, tentu saja memerlukan biaya yang cukup lumayan Metode yang digunakan seperti dengan cara perendaman dalam larutan bahan kimia, baik panas, maupun dingin. Dan impregnasi ke dalam kayu dengan konsentrasi tertentu.

Selain pengawetan dengan cara tersebut kayu dapat pula diperlakukan untuk perbaikan sifat fisik mekanik kayu kelas kuat rendah dengan melalui proses pemadatan. Salah satu upaya mengatasi permasalahan semakin minimnya ketersediaan jenis kayu berkualitas, untuk keperluan bahan bangunan perumahan adalah dengan melakukan perbaikan sifat fisik mekanik kayu, sehingga jenis kayu kelas kuat rendah dapat digunakan sebagai bahan bangunan yang berkualitas (Suroto, 2008).

\section{BAHAN PENGAWET KAYU}

Bahan pengawet kayu ialah bahanbahan kimia yang telah ditemukan dan beracun terhadap mahluk perusak kayu, antara lain tembaga $(\mathrm{Cu})$, seng $(\mathrm{Zn})$, flour $(\mathrm{F})$, krom $(\mathrm{Cr})$ dan lain-lain. Tidak semua bahan pengawet baik digunakan dalam pengawetan kayu. Dalam penggunaan harus diperhatikan sifat-sifat bahan pengawet agar sesuai tujuan pemakaian. 
Sebagai syarat bahan pengawet yang baik

1. Bersifat racun terhadap mahluk perusak kayu.

2. Mudah masuk dan tetap tinggal di dalam kayu.

3. Bersifat permanen tidak mudah luntur atau menguap.

4. Bersifat toleran terhadap bahan-bahan lain misalnya logam, perekat dan cat/finishing.

5. Tidak mempengaruhi kembang susut kayu.

6. Tidak merusak sifat-sifat kayu seperti sifat fisik, mekanik dan kimia.

7. Tidak mudah terbakar atau mempercepat bahaya kebakaran.

8. Tidak berbahaya bagi manusia dan hewan peliharaan.

9. Mudah dikerjakan, diangkut, mudah didapat dan murah.

Pada waktu pengawet kayu harus diperhatikan hal-hal sebagai berikut :

- Di mana kayu itu akan dipakai setelah diawetkan.

- Mahluk perusak kayu apa yang terdapat ditempat tersebut.

- Syarat-syarat kesehatan harus diperhatikan.

\section{PEMBAHASAN}

Dengan semakin sulitnya mendapatkan kayu komersial yang berkualitas dan harganya cukup mahal, maka pengguna kayu yaitu masyarakat maupun pengusaha mebel sudah mulai memikirkan jenis-jenis kayu yang mungkin dapat digunakan untuk mensubstitusi kekurangan kayu komersial tersebut, diantaranya dengan menggunakan kayu kualitas rendah, maupun kayu kurang dikenal. Dengan banyaknya penelitian kayu yang telah dilakukan oleh para peneliti maupun mahasiswa di perguruan tinggi seperti jenis kayu kualitas rendah dan kayu kurang dikenal, sehingga sebahagian masyarakat sudah mulai mengerti dan menggunakan jenis kayu-kayu dimaksud untuk dikembangan penggunaannya dalam pembangunan perumahan maupun pembuatan mebel. Potensi kayu kualitas rendah dan kayu kurang dikenal cukup menjanjikan sebagai substitusi bahan baku kayu komersial dan terdapat di setiap daerah. Hanya yang menjadi masalah karena kayu - kayu dimaksud banyak yang tidak diketahui tentang sifat fisis dan mekanisnya. Oleh karena klasifikasi kelas kuat dan kelas awet kayu banyak yang belum diketahui dengan pasti, dengan demikian jika ingin menggunakan kayu kurang dikenal, sebaiknya diketahui lebih dahulu kelas kuat atau kualitas kayu dengan cara melakukan pengujian terhadap sifat fisis mekanis kayu, sifat kimiawi kayu dan pengawetan kayu tradisional. Penelitian tentang kelas kuat dan kelas awet kayu memang perlu dilakukan agar dalam penggunaan kayu bisa lebih jelas. Tujuan para peneliti tentunya adalah memanfaatkan jenis kayu kualitas rendah dan kayu kurang dikenal agar dapat dimanfaatkan secasa optimal.

\section{KESIMPULAN}

Kayu komersial yang berkualitas makin sulit didapatkan dan harganya yang makin mahal. Seiring dengan pertambahan jumlah penduduk, eksploitasi hutan yang terus menerus dan pembangunan semakin meningkat, sehingga ada indikasi keberadaan kayu komersial di hutan sudah menghawatirkan.

Dengan berkembangnya penelitian tentang kayu kualitas rendah dan kayu kurang dikenal, baik dengan cara fisis mekanis, kimia, proses pengempaan dan lainnya, maka orang mulai banyak menggunakan jenis kayu kualitas rendah sebagai bahan bangunan, selain bahan bangunan, kayu kualitas rendah dapat pula digunakan sebagai bahan baku industri.

Penggunaan bahan pengawet kayu harus sesuai dengan ketentuan yang sudah dipersyaratkan, hal itu dimaksudkan agar dapat meningkatkan daya tahan kayu dan tidak berdampak terhadap kesehatan dan lingkungan sekitarnya. Komponen kimia kayu diperlukan untuk mengetahui kegunaan jenis kayu dan membedakannya. 


\section{DAFTAR PUSTAKA}

1. Anonim, 1976 dalam Arsad E. (2008). ASTM Standard Methods Of Testing Small Clear Specimens Of Timber. D.143 - 52 Annual Book Of ASTM Standard. Part 22 Wood Adhesives. Philadelphia. USA.

2. Anonim, 1999. Dalam Nurwati $\mathrm{H}$, (2004). Buku Panduan Kehutanan Indonesia. Badan Penelitian dan Pengembangan Kehutanan Indonesia. Jakarta.

3. Anonim, 2005. Kemasan Kayu Indonesia Dalam Rangka Penerapan ISPM 15. Jakarta.

4. Harsono, D, 2008. Pemanfaatan Batang Kelapa Sebagai Bahan Baku Industri. Kumpulan Hasil Penelitian Bidang Kayu Rotan dan Bambu.

5. Hamdi S., 2010. Pengolahan Kayu Kelas Kuat Rendah Dengan Impregnasi Bahan Stabilisator Untuk Bahan Baku Kerajinan Dan Mebel. Kumpulan Hasil Penelitian Bidang Kayu, Rotan dan Bambu. Baristand Industri Banjarbaru.

6. Ismediyanto, $2008 . \quad$ Penelitian Pemanfaatan Serbuk Gergaji Kayu Jati Untuk Bata Beton. Jurusan Teknik Sipil.

7. Krisdianto, 2006. Anatomi dan Kualitas Serat Lima Jenis Kayu Kurang Dikenal dari Lengkong Sukabumi. Jurnal Penelitian Hasil Hutan. Bogor.

8. Laban, B.Y, 2005. Prospek Produk Industri Hasil Hutan Indonesia. Paper dalam Seminar Kesiapan Indonesia Dalam Implementasi ISPM. Solid Wood Packaging Material. Pusat Standardisasi dan Lingkungan, Sekjen Departemen Kehutanan, Jakarta.

9. Mardikanto, 2011. Sifat Mekanis Kayu. Institut Pertanian Bogor Press. Bogor.

10. Martono D. 2010. Pengetahuan bahan finishing kayu. Makalah disampaikan pada Diklat Peningkatan Performance Dekoratif, Warna dan Serat kayu Akasia Mangium untuk Mebel. tanggal 9 sampai 15 Februari 2010. Kerjasama JICA Jepang dengan Baristand Industri Banjarbaru.

11. Nurwati, H, 2004. Sifat Fisik Dan Mekanik Kayu Dan Bambu. Pusat Litbang Teknologi Hasil Hutan. Badan litbang Kehutanan. Departemen Kehutanan. Bogor.

12. Pasaribu, dkk. 2007. Analisis Komponen Kimia Empat Jenis Kayu Asal Sumatera Utara. Jurnal Penelitian Hasil Hutan. 25(4):327-333.

13. Pandit IKM, Kurniawan D 2008. Anatomi kayu : Struktur Kayu, Kayu sebagai Bahan Baku dan 52irri Diagnostik Kayu Perdagangan Indonesia. Fakultas Kehutanan Institut Pertanian Bogor, Bogor.

14. Prayitno, T.A. 1997 di dalam Nurwati, 2004. Penggunaan kayu bermutu rendah. Bulletin. Kehutanan No. 12/1997. Fak. Kehutanan Gajah mada. Yogyakarta. Indonesia.

15. Sunardiyanto E, 2012. Teknologi Kayu Bambu dan Serat. Fakultas Teknologi Pertanian. Universitas Brawijaya. Malang.

16. Soewarsono PH.1990 dalam Jurnal Riset Hasil Hutan 2010. Specific Gravity Of Indonesian Woods and its Significance for Practical Use.

17. Suroto, 2008. Perbaikan Sifat Kayu Kelas Kuat Rendah Dengan Teknik Pengempaan. Warta Balai Industri Banjarbaru. Balai Riset dan Standardisasi Industri Banjarbaru. XXIII (2).

18. Sulistiyono, dkk. 2002. Teknik Rekayasa Pemadatan Kayu I. Pusat Penelitian dan Pengembangan Hasil Hutan, Bogor.

19. Surjokusumo, SM, 2005. Karakteristik Mutu Bahan Baku Kemasan di Indonesia. Di Dalam Laporan Seminar Nasional Peningkatan dan Pengawasan Mutu Kemasan Kayu Indonesia Dalam Rangka Penerapan ISPM 15. Di Jakarta. 
20. USDA, 1999. Wood Handbook, Wood as an Engineering Material. Forest Prod. Society. Madison. USA.

21. Wahyu, D dan Nugroho, M. 2008. Tinjauan Hasil-hasil Penelitian Faktorfaktor Alam yang Mempengaruhi Sifat Fisik dan Mekanik Kayu Indonesia. Jurnal IImu dan Teknologi ayu Tropis. Masyarakat Peneliti Kayu Indonesia. 5(1):5-100. 